\title{
Evaluation of Sella Turcica Shape and Dimensions in Cleft Subjects Using Cone-Beam Computed Tomography
}

\author{
Yasin Yasa $^{\text {a }}$ Ibrahim Sevki Bayrakdar ${ }^{b}$ Ali Ocak ${ }^{c}$ Suayip Burak Duman ${ }^{d}$ \\ Numan Dedeoglu ${ }^{d}$ \\ ${ }^{a}$ Department of Maxillofacial Radiology, Faculty of Dentistry, Ordu University, Ordu, ${ }^{b}$ Eskişehir Osmangazi \\ University, Eskişehir, ' Ataturk University, Erzurum, and dinönü University, Malatya, Turkey
}

\section{Key Words}

Cleft lip and palate $\cdot$ Morphology · Sella turcica .

Cone-beam computed tomography

\begin{abstract}
Objective: The aim of this study was to assess the morphology of the sella turcica and measure its size in cleft and noncleft subjects. Material and Methods: Cone-beam computed tomography (CBCT) images of 54 individuals (29 males; 25 females) with cleft and 85 (22 males; 63 females) without cleft were used for this study. Syndromic patients with cleft(s) were not included because of possible additional endocrinological and/or morphological disorders. Linear measurements included length, depth, and diameter. The shape of the sella turcica was analyzed in the cleft and noncleft groups. An independent $t$ test was conducted to evaluate differences between genders and groups. One-way ANOVA was used to compare age groups. Results: The length ( $p<$ $0.001)$ of the sella turcica was smaller in noncleft subjects than in cleft subjects. Diameter $(p=0.014)$ and depth $(p=$ 0.005 ) showed as constantly increasing from an age $<15$ to $>25$ years in the overall assessment. The distribution of the
\end{abstract}

\begin{tabular}{ll}
\hline KARGER & @ 2016 S. Karger AG, Basel \\
$\begin{array}{l}\text { E-Mail karger@karger.com } \\
\text { www.karger.com/mpp }\end{array}$ & $\begin{array}{l}\text { This is an Open Access article licensed under the terms of the } \\
\text { Creative Commons Attribution-NonCommercial 3.0 Un- } \\
\text { ported license (CC BY-NC) (www.karger.com/OA-license), } \\
\text { applicable to the online version of the article only. Distribu- } \\
\text { tion permitted for non-commercial purposes only. }\end{array}$
\end{tabular}

shape of the sella turcica differed significantly between groups ( $p<0.001)$. Conclusions: In this study, CBCT was used to assess the morphology of the sella turcica. A majority of the subjects with cleft had a flattened sella turcica compared to that of the control group. A shorter length of the sella turcica was more evident in the cleft subjects than in the control group.

(c) 2016 S. Karger AG, Basel

\section{Introduction}

The sella turcica is an important saddle-shaped structure that houses the pituitary gland and is located in the middle cranial fossa [1]. The structure consists of anterior and posterior clinoid processes, the tuberculum sella, and the pituitary fossa. The tuberculum sella is the slight anterior elevation on the body of the sphenoid bone. The pituitary fossa is a saddle-like depression in the middle that holds the pituitary gland, and the dorsum sella is formed by a square plate of bone on the body of the sphenoid [2].

Lip and palate clefts are considered the most prevalent craniofacial congenital anomaly. Some studies have

Dr. Yasin Yasa

Department of Maxillofacial Radiology, Faculty of Dentistry, Ordu University 94. Sokak, No:2

TR-52100 Ordu (Turkey)

E-Mail yasayasin@yahoo.com 

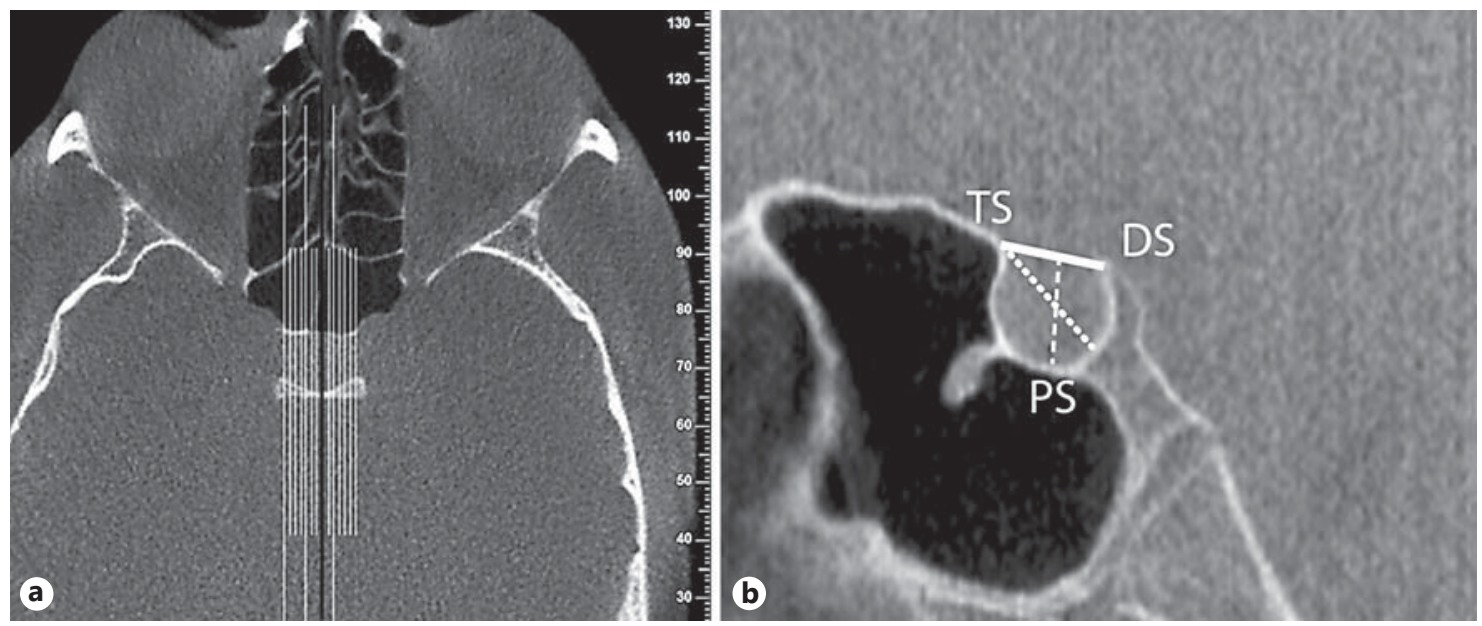

Fig. 1. a The black line shows the midsagittal slice selected as a reference view for the measurement of length, diameter, and depth. $\mathbf{b}$ The reference lines used for measuring the sella turcica size on the midsagittal slice: bold line, length of sella; dashed line, depth of sella; dotted line, diameter of sella. TS, tuberculum sella; DS, dorsum sella; PS, pituitary fossa.

been conducted on the causes of cleft, as well as on the development of craniofacial structures in people with clefts $[1,3]$. Close interactions exist during the development of the hypothalamus, pituitary gland, and oral cavity in early embryonic life $[1,4]$. Any defect in the development of these tissues may lead to anatomical and functional disorders [5]. Many studies have focused on the morphology of the sella turcica and the relationship between its dimensions and general craniofacial deviations [6-9].

The effect of deviations in the morphology of the sella turcica in individuals with clefts has been reported in several 2-dimensional cephalometric studies $[3,4,10]$. However, the 2-dimensional representation of an abnormality does not actually provide complete information about its structure [4]. Only advanced imaging techniques such as computed tomography (CT) or cone-beam (CB)CT can generate more precise information about the sellar region [4]. CBCT produces hard-tissue images of a similar quality to those of CT. However, the images are obtained with less expensive equipment and components, a reduced patient examination time, and a significantly lower radiation dose than with conventional CT [11]. To date, no study has assessed the sella turcica in cleft patients by means of a 3-dimensional imaging system such as CBCT or CT. Therefore, in this study, we aimed to compare the size and shape of the sella turcica between cleft and noncleft individuals on CBCT.

Sella Turcica Morphology in Cleft Subjects

\section{Material and Methods}

The CBCT images of 54 individuals ( 29 males and 25 females) were evaluated as the cleft group at the Faculty of Dentistry, İnönü University, Malatya, Turkey. Surgically repaired cleft lip and/or palate (unilateral or bilateral) were analyzed. We excluded syndromic patients with cleft(s) because of the possible additional endocrinological and/or morphological disorders. For comparison purposes, a control group of 85 patients ( 63 females and 22 males) for whom CBCT examinations were performed for any reason was randomly selected from the archives. All subjects were divided into 3 age groups: $<16$ years, $16-24$ years, and $>24$ years. This categorization was made because growth and development in the sellar region mainly end before the age of $10-15$ years $[12,13]$.

The CBCT images were obtained with the patient in a standard supine position (scanning time, 14-18 s; field of view, $18 \times 13 \mathrm{~cm}$; exposure time, $3.6 \mathrm{~s} ; \mathrm{kV}=110 ; \mathrm{mA}=1-11$; voxel size, $0.2 \mathrm{~mm}^{3}$ ) using the same device (NewTom 5G, QR Verona, Italy). The head of the patient was placed in a horizontal position so that the Frankfort horizontal plane was perpendicular to the table, and the head within the circular gantry housing the X-ray tube to ensure consistent orientation of the sagittal images. All images were assessed by NNT Viewer software.

One of the axial views of the dorsum sella was selected as a reference view. Subsequently, 1-mm sagittal slices, which were made from each corresponding slice of the midsagittal plane, were selected for the measurement of the depth, diameter, length, and shape of the sella turcica (Fig. 1). The following distances were measured: the length from the tip of the dorsum sella to the tuberculum sella; the depth as a perpendicular from the line extending to the deepest point of the sellar floor; and the diameter as the furthest point on the posteroinferior aspect of the pituitary fossa to the most superior point on the tuberculum sella. The sella turcica is described using basic shapes (oval, round, and flattened) according to the sellar floor on the midsagittal images (Fig. 2). 

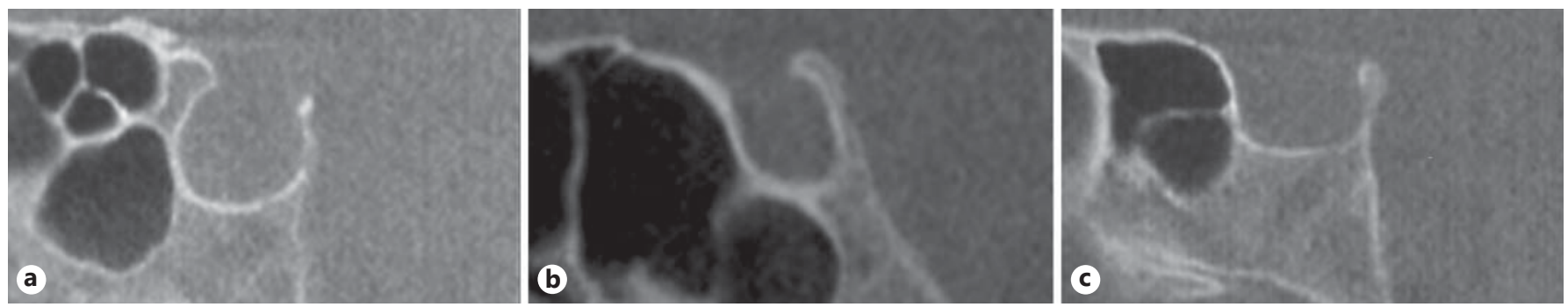

Fig. 2. Different morphology of sella turcica. a Round. b Oval. c Flattened.

Table 1. Dimensions of the sella turcica in the subjects according to gender

\begin{tabular}{|c|c|c|c|c|c|c|c|c|c|}
\hline & \multicolumn{3}{|l|}{ Cleft group } & \multicolumn{3}{|c|}{ Control group } & \multicolumn{3}{|c|}{ Total assessment } \\
\hline & $\begin{array}{l}\text { female } \\
(n=25)\end{array}$ & $\begin{array}{l}\text { male } \\
(n=29)\end{array}$ & $p$ & $\begin{array}{l}\text { female } \\
(n=22)\end{array}$ & $\begin{array}{l}\text { male } \\
(n=63)\end{array}$ & $p$ & $\begin{array}{l}\text { female } \\
(n=47)\end{array}$ & $\begin{array}{l}\text { male } \\
(n=92)\end{array}$ & $p$ \\
\hline Diameter, mm & $11.84 \pm 1.59$ & $11.80 \pm 1.56$ & 0.924 & $11.69 \pm 1.26$ & $11.11 \pm 1.64$ & 0.969 & $11.74 \pm 1.35$ & $11.51 \pm 1.62$ & 0.370 \\
\hline Depth, mm & $7.64 \pm 1.17$ & $7.83 \pm 1.40$ & 0.581 & $7.51 \pm 1.13$ & $7.55 \pm 1.07$ & 0.883 & $7.55 \pm 1.14$ & $7.71 \pm 1.27$ & 0.429 \\
\hline Length, mm & $10.72 \pm 1.77$ & $10.92 \pm 1.93$ & 0.685 & $9.78 \pm 1.55$ & $9.80 \pm 1.24$ & 0.091 & $10.05 \pm 1.66$ & $10.44 \pm 1.75$ & 0.194 \\
\hline
\end{tabular}

Values are mean $\pm \mathrm{SD}$; independent $t$ test.

A radiologist (S.B.D.) with 4 years of experience performed all the measurements. To define the intraobserver error rate, the linear and morphological measurements were repeated on randomly selected images after 1 month, based on the intraclass evaluation rule [14].

\section{Statistical Analysis}

SPSS v20.0 for Windows (SPSS Inc., Chicago, IL, USA) was used for all statistical analyses. Kolmogorov-Smirnov statistics were used for the normality test. An independent $t$ test was conducted to evaluate differences in sella turcica measurements between genders and groups. One-way ANOVA was applied to compare the sella turcica size measurements across different age groups. $p=0.05$ was considered statistically significant.

\section{Results}

The mean age of the cleft group was $18.09 \pm 6.27$ years (range 9-33 years), and that of the control group $19.28 \pm$ 5.66 years (range $7-33$ years). The mean dimensions of the sella turcica in subjects based on gender are shown in Table 1. Independent-sample $t$ tests that compared the measurements of the sella turcica between the genders did not show any significant difference overall $(p>0.05)$ or within the groups $(p>0.05)$.

The dimensions of the sella turcica in the cleft and control groups are shown in Table 2. Generally, the overall size of the sella turcica was smaller in the controls than in
Table 2. Dimensions of the sella turcica

\begin{tabular}{lrrr}
\hline & $\begin{array}{l}\text { Cleft group } \\
(n=54)\end{array}$ & $\begin{array}{l}\text { Control group } \\
(n=85)\end{array}$ & $p$ \\
\hline Diameter, mm & $11.82 \pm 1.56$ & $11.54 \pm 1.38$ & 0.276 \\
Depth, mm & $7.74 \pm 1.29$ & $7.52 \pm 1.11$ & 0.285 \\
Length, mm & $10.83 \pm 1.84$ & $9.78 \pm 1.47$ & $0.001^{*}$ \\
\hline
\end{tabular}

Values are mean \pm SD. Independent $t$ test; ${ }^{*} \mathrm{p}<0.001$.

Table 3. The distribution of different shapes of sella turcica in the groups

\begin{tabular}{lclll}
\hline Shape & $\begin{array}{l}\text { Cleft group, } \\
n(\%)\end{array}$ & $\begin{array}{l}\text { Control group, } \\
n(\%)\end{array}$ & $\begin{array}{l}\text { Total assessment, } \\
n(\%)\end{array}$ & $\chi^{2}$ \\
\hline Oval & $3(5.6)$ & $14(16.4)$ & $17(12.2)$ & $0.000^{*}$ \\
Round & $29(53.7)$ & $61(71.8)$ & $90(65.3)$ & \\
Flattened & $22(40.7)$ & $10(11.8)$ & $32(22.5)$ & \\
\hline Total & $54(100)$ & $85(100)$ & $139(100)$ & \\
\hline \multicolumn{7}{c}{$\chi^{2}$ test; ${ }^{*} \mathrm{p}<0.0001}$. \\
\hline
\end{tabular}

the cleft group, and a significant difference was noted in the length of the sella turcica $(p<0.001)$.

The general distribution of morphological appearances of the sella turcica in the cleft and control groups is 

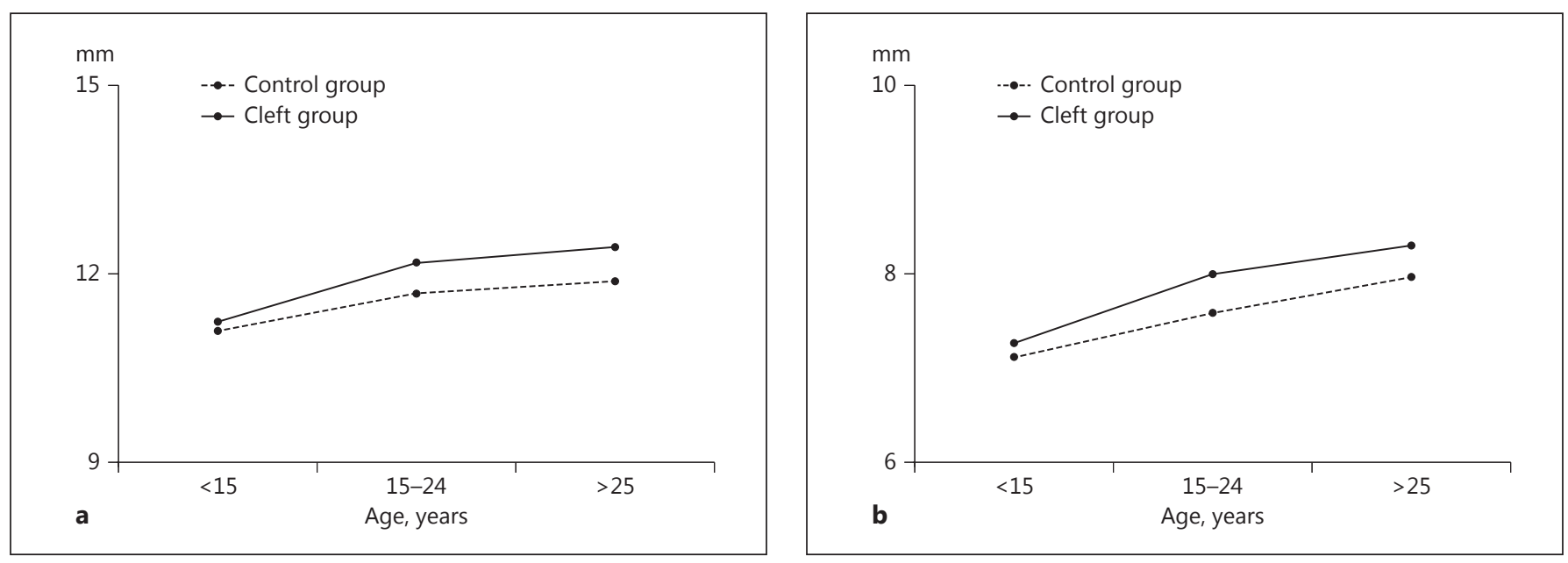

Fig. 3. Graphical illustrations of the diameter (a), depth (b), and length (c) of the sella turcica in the cleft group versus the control group.

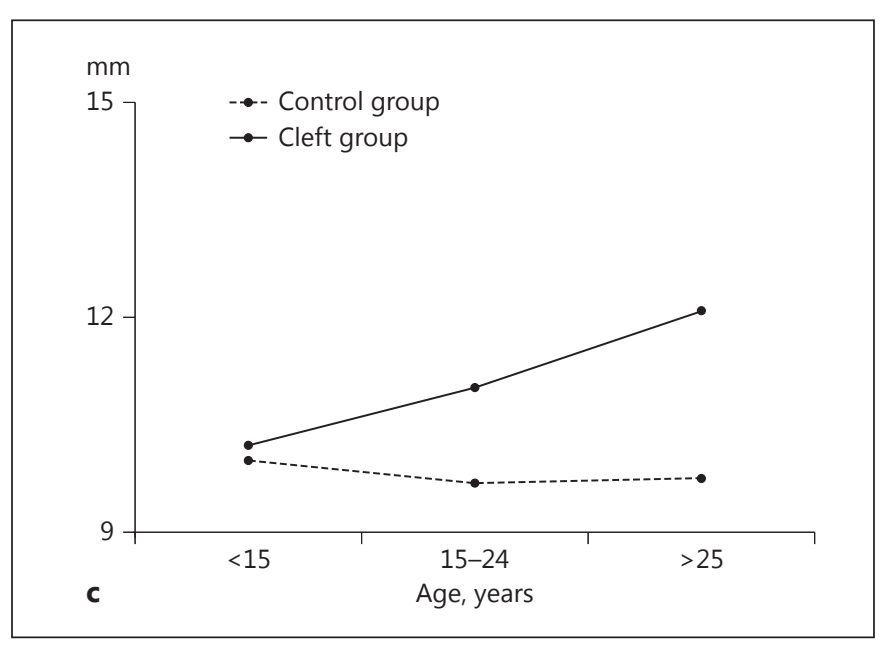

Table 4. All measurements of the sella turcica according to age group

\begin{tabular}{|c|c|c|c|c|c|c|c|c|c|c|c|c|}
\hline & \multicolumn{4}{|l|}{ Cleft group } & \multicolumn{4}{|c|}{ Control group } & \multicolumn{4}{|c|}{ Total assessment } \\
\hline & $\begin{array}{l}<15 \text { years } \\
(n=22)\end{array}$ & $\begin{array}{l}15-24 \text { years } \\
(n=25)\end{array}$ & $\begin{array}{l}>25 \text { years } \\
(n=7)\end{array}$ & $p$ & $\begin{array}{l}<15 \text { years } \\
(n=25)\end{array}$ & $\begin{array}{l}15-24 \text { years } \\
(n=44)\end{array}$ & $\begin{array}{l}>25 \text { years } \\
(n=16)\end{array}$ & $p$ & $\begin{array}{l}<15 \text { years } \\
(n=47)\end{array}$ & $\begin{array}{l}15-24 \text { years } \\
(n=69)\end{array}$ & $\begin{array}{l}>25 \text { years } \\
(n=23)\end{array}$ & $p$ \\
\hline Diameter, mm & $11.2 \pm 1.52$ & $12.1 \pm 1.62$ & $12.4 \pm 0.83$ & 0.064 & $11.09 \pm 1.30$ & $11.68 \pm 1.34$ & $11.88 \pm 1.54$ & 0.134 & $11.16 \pm 1.39$ & $11.86 \pm 1.45$ & $12.05 \pm 1.37$ & $0.014^{*}$ \\
\hline Depth, mm & $7.27 \pm 1.13$ & $8.00 \pm 1.38$ & $8.30 \pm 1.07$ & 0.071 & $7.12 \pm 0.92$ & $7.59 \pm 1.13$ & $7.97 \pm 1.17$ & $0.046^{*}$ & $7.19 \pm 1.02$ & $7.74 \pm 1.23$ & $8.07 \pm 1.13$ & $0.005^{*}$ \\
\hline Length, mm & $10.2 \pm 1.85$ & $11.0 \pm 1.68$ & $12.0 \pm 1.86$ & $0.048^{*}$ & $10.0 \pm 1.47$ & $9.68 \pm 1.50$ & $9.75 \pm 1.46$ & 0.693 & $10.10 \pm 1.64$ & $10.16 \pm 1.68$ & $10.46 \pm 1.89$ & 0.693 \\
\hline
\end{tabular}

Values are mean \pm SD. One-way ANOVA; ${ }^{*} \mathrm{p}<0.05$.

provided in Table 3. The results show that the sella turcica presented with a round shape in the majority of subjects in both groups. A flattened shape (in 40.7\%) was observed frequently in the cleft group but rarely in the control group (in 11.8\%). The morphological features were significantly different between the groups $(p<$ $0.001)$.

The dimensions of the sella turcica based on age in both groups are given in Table 4 . In the cleft group, the

Sella Turcica Morphology in Cleft Subjects measurements of the sella turcica were highest in the group aged $>25$ years and lowest in the group aged $<15$ years. A steady increase was noted in all dimensions along with age (Fig. 3). However, the difference was only statistically significant regarding the length of the sella turcica $(p<0.05)$. In the control group, the depth of the sella turcica differed significantly according to age $(p<$ 0.05). 


\section{Discussion}

In this study, no significant difference was observed in all measurements of the sella turcica in males and females in both groups. This finding confirmed those of Shah et al. [15] and Valizadeh et al. [16], who reported no statistically significant difference between males and females in the length, depth, or diameter of the sella turcica in their normal-orthodontics population. However, the studies by Axelsson et al. [17] and Sathyanarayana et al. [18] reported substantial gender variance in the length of the sella turcica; males exhibited a greater length than females. These differences across studies could be due to the fact that the study samples belonged to different age groups. The pubertal growth spurt is different between males and females $<15$ years old.

The sella turcica is formed at the most cranial extent of the notochord, and deviations in all cranial fields are believed to be associated with deviations in the sella turcica as well. The pituitary gland begins to develop before the formation of the surrounding sella turcica. This relationship implies the existence of mechanical coordination in the growth of the pituitary gland alongside its enclosing skeletal compartment and may cause variations in the size of the gland, which are reflected in the shape and size of the sella turcica. Although some studies have demonstrated a relationship between cleft lip and palate [19-21], Van der Plas et al. [22] claimed that the pituitary is not involved in differences in isolated cleft lip and palate. In our study, there were differences between the cleft group and the control group in terms of the shape and size of the sella turcica, but it was only the length of the sella turcica that was higher in the cleft group than in the control group. However, Alkofide [10], Sundareswaran and Nipun [4], and Axelsson et al. [6], in studies that made use of cephalograms, reported a statistically significant decrease in all dimensions of the sella turcica in cleft patients. The discrepancy here could be due to the fact that conventional radiograms are generally not as accurate as advanced imaging techniques.

In this study, we used basic shapes (oval, round, and flattened) to classify the sella turcica, and found round to be the most frequent shape in the overall assessment. A difference between the groups was found in the distribution of the sella turcica shape. A flattened shape was found more commonly in the cleft group than in the control group. Authors have developed several methods to understand the shape of the sella turcica. These classifications are based on the contours of the sellar floor and the angles formed by the contours of the anterior and posterior clinoid processes and the tuberculum sella [23-25]. Several studies have emphasized the frequency of flat or convex floors, but they only employed plain radiography $[26,27]$. In a case report of the use of CT, Matsui et al. [28] described the sellar floor as flattened rather than shallow; this observation was related to a pathological condition. Ruiz et al. [29] examined the sella turcica in adult human skulls using CT, and classified the shapes as "U", "J", and "shallow", found in 48, 41, and $11 \%$ of the cases, respectively. Alkofide [10] categorized the shapes of the sella turcica as 6 different types on cephalogram (i.e., normal sella turcica, oblique anterior wall, sella turcica bridging, double contour of the floor, irregularity [notching] in the posterior part of the dorsum sella, and a pyramidal shape of the dorsum sella). They also revealed that morphological aberrations in cleft subjects are more common than the normally shaped sella turcica. The results obtained by Alkofide [10] conformed to the findings of a similar study using radiographs of 40 newborns, by Nielsen et al. [3]. The examined newborns had cleft lip and palate, and their work demonstrated deviations in sella morphology in approximately half of the cases. However, the majority of severe deviations were in the newborns with a cleft. Describing these differences, Kjær [1] noted that the bottom part of their sella appeared narrow, which was attributed to deformities of the cleft lip and palate subject's anterior and posterior walls.

The length of the sella turcica in the cleft group and the depth in the control group were affected by age. In the overall assessment, the diameter and depth of the sella turcica constantly increased with age Argyropoulou et al. [30] conducted a retrospective MRI study, which revealed that an age-related increase in the size of the sella turcica is probable because its contents (pituitary gland) increase with age. Alkofide [10] divided radiographs into 2 groups according to age: $10-14$ years and $\geq 15$ years. They found a significant increase in length, depth, and diameter in both noncleft and cleft subjects. According to findings by Choi et al. [24], the size of the sella turcica displays a positive linear tendency before the age of 25 years. Beyond 26 years of age, the dimensional changes of the sella turcica become dormant. 


\section{Conclusions}

In this study, a majority of the cleft subjects had a flattened sella turcica compared to the control group. Equally, a shorter sella turcica was more evident in the cleft subjects than in the controls. CBCT can be used to assess the sella turcica, and further studies on how the dimensions of the sella turcica are interrelated with pathological conditions should be conducted with the use of advanced imaging methods.

\section{References}

1 Kjær I: Sella turcica morphology and the pituitary gland - a new contribution to craniofacial diagnostics based on histology and neuroradiology. Eur J Orthod 2015;37:28-36.

2 Tekiner H, Acer N, Kelestimur F: Sella turcica: an anatomical, endocrinological, and historical perspective. Pituitary 2015;18:575578

3 Nielsen BW, Molsted K, Kjær I: Maxillary and sella turcica morphology in newborns with cleft lip and palate. Cleft Palate Craniofac J 2005;42:610-617.

4 Sundareswaran S, Nipun CA: Bridging the gap: sella turcica in unilateral cleft lip and palate patients. Cleft Palate Craniofac J 2015;52: 597-604.

5 Osman M, Allan JC, Kramer B: A pharyngeal and ectopic hypophysis in a neonate with craniofacial abnormalities: a case report and review of development and structure. Cleft Palate Craniofac J 2006;43:117-122.

6 Axelsson S, Storhaug K, Kjaer I: Post-natal size and morphology of the sella turcica in Williams syndrome. Eur J Orthod 2004;26: 613-621.

7 Bonneville JF, Cattin F, Dietemann JL: Hypothalamic-pituitary region: computed tomography imaging. Baillieres Clin Endocrinol Metab 1989;3:35-71.

8 Korayem M, AlKofide E: Size and shape of the sella turcica in subjects with Down syndrome. Orthod Craniofac Res 2015;18:43-50.

9 Kucia A, Jankowski T, Siewniak M, et al: Sella turcica anomalies on lateral cephalometric radiographs of Polish children. Dentomaxillofac Radiol 2014;43:20140165.

10 Alkofide EA: Sella turcica morphology and dimensions in cleft subjects. Cleft Palate Craniofac J 2008;45:647-653.
11 Ludlow JB, Ivanovic M: Comparative dosimetry of dental CBCT devices and 64-slice CT for oral and maxillofacial radiology. Oral Surg Oral Med Oral Pathol Oral Radiol Endod 2008;106:106-114.

12 Melsen B: The cranial base: the postnatal development of the cranial base studied histologically on human autopsy material. Am J Orthod 1974;66:689-691.

13 Bjork A, Skieller V: Normal and abnormal growth of the mandible. A synthesis of longitudinal cephalometric implant studies over a period of 25 years. Eur J Orthod 1983;5:1-46.

14 Shoukri MM: Measures of Interobserver Agreement, ed 2. Boca Raton, CRC Press, 2010, pp 50-51.

15 Shah AM, Bashir U, Ilyas T: The shape and size of the sella turcica in skeletal class I, II \& III in patients presenting at Islamic International Dental Hospital, Islamabad. Pakistan Oral Dent J 2011;31:104-110.

16 Valizadeh S, Shahbeig S, Mohseni S, et al: Correlation of shape and size of sella turcica with the type of facial skeletal class in an Iranian group. Iran J Radiol 2015;12:1-7.

17 Axelsson S, Storhaug K, Kjaer I: Post-natal size and morphology of the sella turcica. Longitudinal cephalometric standards for Norwegians between 6 and 21 years of age. Eur J Orthod 2004:26:597-604.

18 Sathyanarayana HP, Kailasam V, Chitharanjan AB: The size and morphology of sella turcica in different skeletal patterns among south Indian population: a lateral cephalometric study. J Indian Orthod Soc 2013;47:266-271.

19 Sultan Z, Gnanaratnam J, Sharief N: Isolated aplasia of the anterior pituitary gland with unusual associations. Clin Dysmorphol 1996;5: $347-350$
20 Zimmerman TS, White MG, Daughaday $\mathrm{WH}$, et al: Hypopituitarism with normal or increased height. Am J Med 1967;42:146-150.

21 Akin MA, Kurtoğlu S, Sarici D, et al: Endocrine abnormalities of patients with cleft lip and/or cleft palate during the neonatal period. Turkish J Med Sci 2014;44:696-702.

22 Van der Plas E, Caspell CJ, Aerts AM, et al: Height, BMI, and pituitary volume in individuals with and without isolated cleft lip and/or palate. Pediatr Res 2012;71:612-618.

23 Becktor JP, Einersen S, Kjaer I: A sella turcica bridge in subjects with severe craniofacial deviations. Eur J Orthod 2000;22:69-74.

24 Choi WJ, Hwang EH, Lee SR: The study of shape and size of normal sella turcica in cephalometric radiographs. Korean J Oral Maxillofac Radiol 2001;31:43-49.

25 Bruneton JN, Drouillard JP, Sabatier JC, et al: Normal variants of the sella turcica. Radiology 1979;131:99-104.

26 Newton TH, Potts DG: Radiology of the Skull and Brain. St Louis, CV Mosby, 1971, pp 357405.

27 McLachlan MS, Wright AD, Doyle FH: Plain film and tomographic assessment of the pituitary fossa in 140 acromegalic patients. $\mathrm{Br}$ J Radiol 1970;43:360-369.

28 Matsui T, Ueno I, Miki Y, et al: Flattened sella turcica and CT appearance of normal pituitary gland. Neuroradiology 1984;26:75-77.

29 Ruiz CR, Wafae N, Wafae GC: Sella turcica morphometry using computed tomography. Eur J Anat 2008;12:47-50.

30 Argyropoulou M, Perignon F, Brunelle F, et al: Height of normal pituitary gland as a function of age evaluated by magnetic resonance imaging in children. Pediatr Radiol 1991;21: 247-249.
Sella Turcica Morphology in Cleft Subjects
Med Princ Pract 2017;26:280-285

DOI: $10.1159 / 000453526$ 